\title{
(2) OPEN ACCESS \\ Firearm access and adolescent suicide risk: toward a clearer understanding of effect size
}

\author{
Sonja A Swanson (1) , ${ }^{1,2}$ Mara Eyllon, ${ }^{3,4}$ Yi-Han Sheu, ${ }^{1}$ Matthew Miller ${ }^{1,4}$
}

- Additional material is published online only. To view please visit the journal online (http://dx.doi.org/10.1136/ injuryprev-2019-043605).

'Department of Epidemiology, Harvard T. H. Chan School of Public Health, Boston, Massachusetts, USA

${ }^{2}$ Department of Epidemiology, Erasmus Medical Center Rotterdam, Netherlands ${ }^{3}$ Boston University School of Medicine and Boston Medical Center, Boston, Massachusetts, USA

${ }^{4}$ Department of Health Sciences, Northeastern University, Boston, Massachusetts, USA

\section{Correspondence to}

Dr Sonja A Swanson, Department of Epidemiology, Erasmus Medical Center, Rotterdam, Netherlands; s. swanson@erasmusmc.n

Received 6 December 2019 Revised 12 March 2020 Accepted 14 March 2020
D Check for updates

(c) Author(s) (or their employer(s)) 2020. Re-use permitted under CC BY-NC. No commercial re-use. See rights and permissions. Published by BMJ.

To cite: Swanson SA, Eyllon M, Sheu Y-H, et al. Inj Prev Epub ahead of print: [please include Day Month Year]. doi:10.1136/

injuryprev-2019-043605

\section{ABSTRACT}

Background Strong and consistent associations between access to firearms and suicide have been found in ecologic and individual-level observational studies. For adolescents, a seminal case-control study estimated that living in a home with (vs without) a firearm was associated with a fourfold increase in the risk of death by suicide.

Methods We use data from a nationally representative study of 10123 US adolescents aged 13-18 years to (1) measure how much adolescents who live in a home with a firearm differ from those who do not in ways related to their risk of suicide, and (2) incorporate these differences into an updated effect estimate of the risk of adolescent suicide attributable to living in a home with firearms. Results Almost one-third (30.7\%) of adolescents reported living in a home with firearms. Relative to those who did not, adolescents reporting living in a home with a firearm were slightly more likely to be male, older and reside in the South and rural areas, but few differences were identified for mental health characteristics. The effect size found by Brent and colleagues appeared robust to sources of possible residual confounding: updated relative risks remained above 4.0 across most sensitivity analyses and at least 3.1 in even the most conservative estimates.

Conclusions Although unmeasured confounding and other biases may nonetheless remain, our updated estimates reinforce the suggestion that adolescents' risk of suicide was increased threefold to fourfold if they had lived in homes with a firearm compared with if they had not.

On an average day in 2017, 10 US children and young adults under the age of 21 died by suicide, making suicide the second leading cause of death in this age group. ${ }^{1}$ Strong and consistent associations between access to firearms and suicide, attributable to elevated firearm suicide, have been found in dozens of ecological and individual-level observational studies across all age groups, ${ }^{2-13}$ with the relative risk among adolescents being particularly large. Indeed, the seminal 1993 case-control study by Brent and colleagues ${ }^{4}$ estimated that living in a home with (vs without) a firearm was associated with a fourfold increase in the risk of death by suicide. Based on these data, Brent and colleagues later estimated that the population attributable risk of suicide among children under 16 years of age was greater for firearms than for major depressive disorder. ${ }^{14}$

Estimates of how many adolescent suicide deaths could be prevented if youths' access to firearms were reduced by a given amount rely on published measures of associations in observational studies. ${ }^{15}$ Interpretation of effect estimates must, therefore, grapple with potential residual confounding: how, if at all, do adolescents who live in a home with a firearm differ from those who do not in ways related to their risk of suicide not accounted for in prior effect estimates. To the extent that residual imbalances in potential confounders can be identified and quantified, this knowledge can be incorporated into the re-estimation of causal effects, which, in turn, can better inform evidence-based public policy, clinical advice and personal decision-making related to access to household firearms.

The most rigorous observational studies to date have accounted for potential confounding in the firearm-suicide relationship by restricting, matching and/or analytically adjusting for some, but not other, demographic characteristics and psychiatric disorders. ${ }^{2}{ }^{4}$ For example, via restriction, matching and analytic adjustment, Brent and colleagues' case-control study with community controls accounted for sex, age, race/ethnicity, socioeconomic status, geographic region, major depressive disorder, conduct disorder and substance use disorder. ${ }^{4}$ Of course, one can argue (as others ${ }^{16}$ have) that these effect estimates remain confounded by other suicide risk factors (eg, other psychiatric disorders).

A recent review and quantitative bias analysis clarified that there is little room for scientific debate regarding whether an unmeasured confounder could completely explain away the estimated non-null effect of household firearms on suicide: no known suicide risk factor is so strongly associated with both firearm access and suicide risk as to be a plausible candidate for an unmeasured confounder that could explain away the observed associations in the published literature, either among adults or among children. ${ }^{17}$ Furthermore, for adults, no meaningful differences in suicide risk factors between persons living in homes with versus without firearms have been found that would alter the broad conclusion that firearm access has a strong effect on suicide risk. ${ }^{17-21}$ However, surprisingly little data have been published on differences (if any) in validated measures of adolescent suicide risk factors between adolescents who live in a home with versus without a firearm.

The current study uses data from a nationally representative study of US adolescents to extend current knowledge in two ways: first, to provide estimates of the association between established adolescent suicide risk factors and living in a home with a firearm; second, to use these estimates to 
empirically adjust previously reported point estimates in the pivotal adolescent case-control study by Brent and colleagues (the only case-control study of firearms and suicide among adolescents who use living community controls). ${ }^{4}$ The refinement our analyses provide in updating prior effect estimates in light of additional information about the magnitude of suicide risk factor imbalance across levels of household gun ownership is a direct empirical response to the rhetorical criticism that unmeasured confounding explains the magnitude or even existence of a causal link between firearm access and suicide risk in youth. In addition, our approach illustrates how future studies can further refine the estimated effect of living in a home with a firearm on suicide risk more broadly.

\section{METHODS}

Data come from the National Comorbidity Survey Replication Adolescent Supplement (NCSA), a nationally representative cross-sectional study of 10123 US adolescents aged 13-18 years. The NCSA is a restricted use, public access dataset for which the Inter-university Consortium for Political and Social Research at the University of Michigan acts as a custodian. The research protocol and data security plan was approved by the Northeastern University Institutional Review Board. There was no patient or public involvement in the conduct of the current study.

Details of the NCSA have been described elsewhere. ${ }^{22-26}$ In brief, adolescents were interviewed in 2001-2004 with the Composite International Diagnostic Interview modified for age appropriateness. In addition, a subset of parents of the adolescents (unweighted $n=6483$ ) completed the Parent SelfAdministered Questionnaire. The measures used in the current study are described below.

\section{Measure of firearm access}

Adolescents were asked 'How many guns that are in working condition do you have in your house, including handguns, rifles, and shotguns?' We used this question to generate our primary measure of firearm access: living in a home without firearms versus living in a home with one or more firearms. Adolescents who responded 'I don't know' $(\mathrm{n}=336)$ or refused $(\mathrm{n}=32)$ were excluded from our analyses (unweighted $\%$ excluded $=3.6 \%$ ).

\section{Measures of suicide risk factors}

We investigated demographic and mental health measures available in the NCSA that have previously been established as predictive of suicide risk in adolescents. This included the following set of demographic covariates: sex, age (categorised as $13-14,15-16$ and $17-18$ years), self-reported race/ethnicity (Hispanic, non-Hispanic black, non-Hispanic white, other), urbanicity (metropolitan, other urban and rural based on 2000 Census definitions), parental education (highest level attained by either parent: less than high school, high school, some college or college graduate), family income (four categories based on the poverty index ratio as below $1.5,1.5$ to less than 3,3 to less than 6 , at or above 6) and family composition (the number of biological parents the adolescent lived with).

Adolescents were assessed for lifetime psychiatric disorders including mood disorders (major depressive disorder, minor depressive disorder, dysthymic disorder, bipolar I disorder, bipolar II disorder), anxiety disorders (generalised anxiety disorder, panic disorder, social phobia, specific phobia, posttraumatic stress disorder, separation anxiety disorder), substance use disorders (alcohol and drug abuse and dependence disorders), behavioural disorders (attention deficit disorder, oppositional defiant disorder, conduct disorder) and eating disorders (anorexia nervosa, bulimia nervosa). These assessments of disorders defined by the Diagnostic and Statistical Manual for Mental Disorders, Fourth Edition, have been previously validated in a subsample of the NCSA ${ }^{22} 25-28$; overall prevalence estimates have been previously reported. ${ }^{23}$ Adolescents also reported lifetime suicidal ideation, plans and attempts. ${ }^{29}{ }^{30}$ In addition to our measures of adolescent mental health, we investigate five single-question measures of maternal mental health reported by the adolescent: maternal sadness/depression, drinking problems, suicide attempts, substance abuse treatment and depression treatment.

\section{Analyses}

We estimated the prevalence of suicide risk factors across adolescents living in a home with versus without a firearm. All analyses accounted for NCSA's complex survey design, using SAS V.9.4 survey procedures with Taylor series linearisation method to estimate the variance.

The prevalence differences of these risk factors across adolescents in homes with versus without firearms were then used to further refine Brent and colleagues' adjusted estimates of the effect of living in a home with versus without a firearm on adolescent suicide risk. Specifically, we took the adjusted estimate presented in Brent and colleagues ${ }^{4}$ as an a priori estimate for the relative risk (ie, a risk ratio (RR) of 4.4), and asked how this estimate would change, in magnitude and direction, if we further adjusted for each of the suicide risk factors available to us in the NCSA but not available in the original study by Brent et al. The proxies available in the NCSA that most closely align with what was previously adjusted for by Brent and colleagues include age, region, education, major depressive disorder, conduct disorder, substance use disorder, parental marital status and poverty status. Because Brent and colleagues' sample was predominantly white, we also considered race/ethnicity previously accounted for (ie, accounted for by restriction rather than analytic adjustment). A summary of how each of our measurements compare to those used by Brent et al appears in the online supplementary materials.

The magnitude and direction of the effect estimate is affected by such confounders through (1) the association between the confounder and living in a home with a firearm (specifically, the prevalence of the confounder in adolescents who lived in homes with vs without firearms), and (2) the relative risk of suicide by levels of that confounder among adolescents who did not live in homes with firearms. ${ }^{31}{ }^{32}$ More specifically, the effect estimate we obtain for the causal risk ratio after adjusting for a previously unmeasured confounder is:

$$
4.4 /\left(\frac{\operatorname{Pr}[\mathrm{L}=1 \mid \mathrm{A}=1] * \mathrm{OR}_{\mathrm{LY} \mid \mathrm{A}}+1-\operatorname{Pr}[\mathrm{L}=1 \mid \mathrm{A}=1]}{\operatorname{Pr}[\mathrm{L}=1 \mid \mathrm{A}=0] * \mathrm{OR}_{\mathrm{LY} \mid \mathrm{A}}+1-\operatorname{Pr}[\mathrm{L}=1 \mid \mathrm{A}=0]}\right)
$$

where $\mathrm{L}$ is the covariate, $\mathrm{A}$ is an indicator of living in a home with versus without a firearm and $\mathrm{OR}_{\mathrm{LY} \mid \mathrm{A}}$ is the $\mathrm{OR}$ of suicide by levels of $\mathrm{L}$ and within levels of A. Our analyses in the NCSA provide estimates for (1); we then consider a range of possible values for (2) from 1 (no association) to 10 (a very strong association). Of note, this formula showcases the intuition that a stronger association between a confounder and living in a home with a firearm (1) and a stronger association between that confounder and risk of suicide (2) would lead to a larger bias.

We further conduct hyperconservative sensitivity analyses in which summary estimates of the adjusted risk ratio under the assumptions that these previously unmeasured confounders' 
Table 1 Prevalence of demographic and mental health characteristics by firearm access

\begin{tabular}{|c|c|c|c|c|c|c|}
\hline & \multicolumn{3}{|c|}{ Prevalence among adolescents living in a home with a firearm } & \multicolumn{3}{|c|}{$\begin{array}{l}\text { Prevalence among adolescents not living in a home with a } \\
\text { firearm }\end{array}$} \\
\hline & Unweighted N & Weighted per cent & $95 \% \mathrm{Cl}$ & Unweighted $\mathrm{N}$ & Weighted per cent & $95 \% \mathrm{Cl}$ \\
\hline \multicolumn{7}{|l|}{ Sex* } \\
\hline Male & 1689 & 58.8 & 55.4 to 62.2 & 3134 & 48.6 & 46.5 to 50.7 \\
\hline Female & 1232 & 41.2 & 37.8 to 44.6 & 3698 & 51.4 & 49.3 to 53.5 \\
\hline \multicolumn{7}{|l|}{ Age $^{*}$} \\
\hline $13-14$ years & 1030 & 31.8 & 26.8 to 36.9 & 2686 & 38.2 & 33.3 to 43 \\
\hline $15-16$ years & 1189 & 44.8 & 39.6 to 50 & 2571 & 40.0 & 36.7 to 43.3 \\
\hline $17-18$ years & 702 & 23.4 & 20.3 to 26.4 & 1575 & 21.8 & 19.4 to 24.2 \\
\hline \multicolumn{7}{|l|}{ Race* } \\
\hline White & 2214 & 82.4 & 78.7 to 86.2 & 3166 & 57.2 & 53.3 to 61 \\
\hline Hispanic & 323 & 8.1 & 4.4 to 11.8 & 1547 & 17.5 & 14.9 to 20.1 \\
\hline Black & 244 & 6.7 & 4.8 to 8.7 & 1655 & 19.3 & 16.5 to 22 \\
\hline Other & 140 & 2.7 & 1.9 to 3.5 & 464 & 6.1 & 4.5 to 7.6 \\
\hline \multicolumn{7}{|l|}{ Poverty index ratio* } \\
\hline$<1.5$ & 331 & 10.8 & 9.1 to 12.5 & 1332 & 16.6 & 14.5 to 18.6 \\
\hline 1.5 to $\leq 3$ & 568 & 17.9 & 15.6 to 20.3 & 1378 & 19.4 & 17.9 to 20.9 \\
\hline 3 to $\leq 6$ & 1042 & 35.3 & 32 to 38.5 & 1942 & 30.3 & 28.4 to 32.2 \\
\hline$>6$ & 980 & 36.0 & 32.1 to 39.9 & 2180 & 33.7 & 31.2 to 36.3 \\
\hline \multicolumn{7}{|l|}{ Geographic region* } \\
\hline Northeastern & 308 & 10.1 & 6.7 to 13.6 & 1516 & 22.1 & 16.2 to 28 \\
\hline Midwest & 970 & 27.8 & 22.4 to 33.1 & 1718 & 21.4 & 16.8 to 26 \\
\hline South & 1164 & 44.0 & 37.2 to 50.9 & 2115 & 32.1 & 26.9 to 37.3 \\
\hline West & 479 & 18.1 & 13.8 to 22.4 & 1483 & 24.4 & 18.7 to 30 \\
\hline \multicolumn{7}{|l|}{ Family structure* } \\
\hline No parents & 236 & 8.6 & 6.4 to 10.8 & 680 & 9.4 & 7.9 to 10.8 \\
\hline One parent & 822 & 26.9 & 23.4 to 30.4 & 2871 & 40.2 & 38.1 to 42.3 \\
\hline Two parents & 1863 & 64.5 & 59.9 to 69.2 & 3281 & 50.4 & 47.8 to 53 \\
\hline \multicolumn{7}{|l|}{ Parental education* } \\
\hline Less than high school & 181 & 5.7 & 4.1 to 7.2 & 713 & 9.4 & 8 to 10.7 \\
\hline High school & 994 & 35.0 & 31.1 to 39 & 1964 & 27.2 & 24.4 to 30.1 \\
\hline Some college & 660 & 21.8 & 19.2 to 24.4 & 1263 & 18.6 & 16.8 to 20.4 \\
\hline College or higher & 969 & 33.2 & 30 to 36.4 & 2288 & 36.2 & 32.4 to 40 \\
\hline \multicolumn{7}{|l|}{ Urbanicity* } \\
\hline Metro & 819 & 34.5 & 29.1 to 39.9 & 3564 & 53.8 & 48.5 to 59.1 \\
\hline Other urban non-metro & 953 & 40.8 & 32.9 to 48.7 & 2239 & 36.2 & 30.3 to 42.2 \\
\hline Rural & 1149 & 24.7 & 18.7 to 30.7 & 1029 & 10.0 & 6.7 to 13.2 \\
\hline \multicolumn{7}{|l|}{ Mood disorders } \\
\hline Major depressive disorder* & 300 & 10.5 & 8.4 to 12.6 & 768 & 10.8 & 9.8 to 11.8 \\
\hline Minor depressive disorder & 31 & 0.8 & 0.4 to 1.2 & 106 & 1.7 & 1.3 to 2 \\
\hline Dysthymic disorder & 81 & 3.5 & 2.3 to 4.8 & 234 & 3.3 & 2.5 to 4 \\
\hline Bipolar I disorder & 40 & 1.5 & 0.8 to 2.2 & 91 & 1.1 & 0.8 to 1.4 \\
\hline Bipolar II disorder & 23 & 1.4 & 0.8 to 2 & 69 & 0.9 & 0.6 to 1.3 \\
\hline \multicolumn{7}{|l|}{ Anxiety disorders } \\
\hline $\begin{array}{l}\text { Generalised anxiety } \\
\text { disorder }\end{array}$ & 69 & 3.2 & 2.1 to 4.3 & 212 & 3.1 & 2.3 to 3.9 \\
\hline Panic disorder & 62 & 2.3 & 1.6 to 3 & 171 & 2.5 & 2 to 3 \\
\hline Agoraphobia & 8 & 0.3 & 0 to 0.7 & 24 & 0.2 & 0.1 to 0.4 \\
\hline Social phobia & 391 & 14.8 & 12.8 to 16.8 & 980 & 14.3 & 13.1 to 15.5 \\
\hline Separation anxiety disorder & 188 & 6.8 & 5.8 to 7.9 & 558 & 8.1 & 7.2 to 8.9 \\
\hline Specific phobia & 530 & 17.8 & 15.6 to 20 & 1381 & 20.2 & 18.3 to 22 \\
\hline $\begin{array}{l}\text { Posttraumatic stress } \\
\text { disorder }\end{array}$ & 103 & 4.9 & 3.3 to 6.5 & 262 & 3.6 & 3 to 4.2 \\
\hline \multicolumn{7}{|l|}{ Substance use disorders } \\
\hline Alcohol abuse disorder* & 246 & 8.4 & 7.2 to 9.7 & 402 & 5.5 & 4.4 to 6.6 \\
\hline $\begin{array}{l}\text { Alcohol dependence } \\
\text { disorder* }\end{array}$ & 45 & 2.3 & 1.3 to 3.3 & 64 & 0.8 & 0.5 to 1.1 \\
\hline
\end{tabular}


Table 1 Continued

\begin{tabular}{|c|c|c|c|c|c|c|}
\hline & \multicolumn{3}{|c|}{ Prevalence among adolescents living in a home with a firearm } & \multicolumn{3}{|c|}{$\begin{array}{l}\text { Prevalence among adolescents not living in a home with a } \\
\text { firearm }\end{array}$} \\
\hline & Unweighted $\mathrm{N}$ & Weighted per cent & $95 \% \mathrm{Cl}$ & Unweighted $\mathrm{N}$ & Weighted per cent & $95 \% \mathrm{Cl}$ \\
\hline Drug abuse disorder* & 282 & 11.0 & 8.5 to 13.5 & 554 & 8.0 & 6.5 to 9.4 \\
\hline $\begin{array}{l}\text { Drug dependence } \\
\text { disorder* }\end{array}$ & 64 & 2.5 & 1.2 to 3.8 & 115 & 1.6 & 1.1 to 2.1 \\
\hline \multicolumn{7}{|l|}{ Behavioural disorders } \\
\hline Conduct disorder* & 140 & 5.0 & 3.5 to 6.6 & 416 & 5.7 & 3.7 to 7.7 \\
\hline Attention deficit disorder & 130 & 4.6 & 3.3 to 5.8 & 274 & 4.0 & 2.9 to 5.1 \\
\hline $\begin{array}{l}\text { Oppositional defiant } \\
\text { disorder }\end{array}$ & 306 & 11.1 & 9.4 to 12.8 & 701 & 9.8 & 8.3 to 11.4 \\
\hline \multicolumn{7}{|l|}{ Eating disorders } \\
\hline Anorexia nervosa & 11 & 0.4 & 0 to 0.8 & 23 & 0.3 & 0.1 to 0.4 \\
\hline Bulimia nervosa & 22 & 0.6 & 0.3 to 0.9 & 66 & 1.0 & 0.6 to 1.5 \\
\hline \multicolumn{7}{|l|}{ Suicidality } \\
\hline Suicidal ideation & 327 & 13.4 & 10.7 to 16.1 & 775 & 11.4 & 10.5 to 12.3 \\
\hline Suicide plan or attempt & 115 & 6.0 & 4.1 to 8 & 312 & 4.4 & 3.7 to 5.1 \\
\hline \multicolumn{7}{|l|}{ Maternal mental health } \\
\hline Mother sad/depressed & 466 & 17.5 & 14.5 to 20.5 & 1265 & 19.8 & 18.1 to 21.4 \\
\hline $\begin{array}{l}\text { Mother had drinking } \\
\text { problem }\end{array}$ & 114 & 4.7 & 3.3 to 6.2 & 250 & 3.7 & 2.9 to 4.5 \\
\hline Mother attempted suicide & 43 & 2.0 & 1.2 to 2.7 & 74 & 1.2 & 0.8 to 1.5 \\
\hline $\begin{array}{l}\text { Mother treated for } \\
\text { depression }\end{array}$ & 166 & 7.1 & 5.5 to 8.8 & 386 & 6.9 & 5.7 to 8 \\
\hline $\begin{array}{l}\text { Mother treated for } \\
\text { substance use }\end{array}$ & 58 & 2.4 & 1.4 to 3.5 & 130 & 1.8 & 1.3 to 2.3 \\
\hline
\end{tabular}

*Indicates a variable that was previously accounted for in the study by Brent and colleagues.

biases are independent of one another and likewise independent of confounding accounted for by Brent et al. This hyperconservative sensitivity analysis is computed by taking the product of the biases estimated for each confounder independently

\section{RESULTS}

Almost one-third (30.7\%) of adolescents reported living in a home with one or more firearms (table 1). Relative to adolescents who did not report living in a home with a firearm, adolescents who reported living in a home with a firearm were more likely to be male (58.8\% vs $48.6 \%$ ), older (eg, $23.4 \%$ vs $21.8 \%$ were ages $17-18$ years), white $(82.4 \%$ vs $57.2 \%)$, reside in the South (44.0\% vs $32.1 \%)$ or Midwest $(27.8 \%$ vs $21.4 \%)$ and reside in rural areas $(24.7 \%$ vs $10.0 \%)$. Few substantial differences were seen with respect to the measures of mental health. Relative to adolescents who did not report living in a home with a firearm, adolescents who reported living in a home with a firearm were somewhat more likely to meet criteria for a substance use disorder (eg, $2.3 \%$ vs $0.8 \%$ for alcohol dependence disorder) and suicide plans or attempts $(6.0 \%$ vs $4.4 \%)$.

The prior relative risk estimate of 4.4 is robust to adjustments for individual covariates (table 2; online supplementary figure). Indeed, even taking the most imbalanced risk factor (eg, suicide plans or attempts) and assuming that risk factor increased suicide risk 10-fold, the adjusted estimate for the relative risk is 3.99 .

Under the extreme assumptions that (1) all risk factors increased the odds of suicide 10-fold and (2) the biases corrected for by adjusting for them are completely independent of one another and the confounding already accounted for in the original Brent et al study, the adjusted estimate for the relative risk would be 3.1 (table 2; online supplementary figure). If instead we assume the suicide odds would increase twofold or fivefold (as opposed to 10-fold), the adjusted estimates are 4.2 and 3.6, respectively (table 2 ; online supplementary figure).

\section{DISCUSSION}

Our findings indicate that the distribution of demographic and mental health characteristics that are known to be risk factors for suicide is relatively similar among adolescents who live in homes with versus without firearms. The exceptions to this finding include characteristics that have been accounted for in the prior case-control study by Brent and colleagues (eg, urbanicity). Given this, it is not surprising that when we quantify confounding we find that it is unlikely to materially change the previously reported estimate that living in a home with a firearm increases adolescents' suicide risk over fourfold, with the most conservative of our sensitivity analyses suggesting an updated estimate closer to threefold. As such, our findings add another analytic dimension of empirical evidence to the assertion that the effect of firearm availability on adolescents' suicide risk is not merely non-null, but meaningfully large in magnitude.

The current study also points to next questions that can be approached using methods analogous to those used herein. For example, the type of analytic approach we used in the current study can be applied to refining estimates of how different firearm storage practices are related to suicide risk among adolescents living in homes with firearms. ${ }^{33}$ Prior work on how adolescents with versus without self-reported 'easy access' to a firearm in their home partly addresses this question, ${ }^{34}$ and suggests that the storage literature is unlikely to be subject to major unmeasured confounding. However, because 'easy access' conflates storage practices and self-assessed capacity to access the firearm given whatever the storage practice may be, the current literature nevertheless leaves room for the line of investigation into storage 
Table 2 Confounder-adjusted risk ratio by proposed confounder and possible associations between the confounder and suicide on the OR scale equal to 2,5 and 10.

\begin{tabular}{|c|c|c|c|}
\hline & $O R=2$ & $\mathrm{OR}=5$ & $O R=10$ \\
\hline \multicolumn{4}{|l|}{ Mood disorders } \\
\hline Minor depressive disorder & 4.44 & 4.55 & 4.73 \\
\hline Dysthymic disorder & 4.39 & 4.37 & 4.34 \\
\hline Bipolar I disorder & 4.38 & 4.33 & 4.26 \\
\hline Bipolar II disorder & 4.38 & 4.32 & 4.22 \\
\hline \multicolumn{4}{|l|}{ Anxiety disorders } \\
\hline Generalised anxiety disorder & 4.40 & 4.38 & 4.37 \\
\hline \multicolumn{4}{|l|}{ Panic disorder } \\
\hline Agoraphobia & 4.40 & 4.38 & 4.36 \\
\hline Social phobia & 4.38 & 4.34 & 4.32 \\
\hline Separation anxiety disorder & 4.45 & 4.58 & 4.72 \\
\hline Specific phobia & 4.49 & 4.65 & 4.77 \\
\hline Posttraumatic stress disorder & 4.35 & 4.21 & 4.04 \\
\hline \multicolumn{4}{|l|}{ Behavioural disorders } \\
\hline Attention deficit disorder & 4.37 & 4.31 & 4.23 \\
\hline Oppositional defiant disorder & 4.35 & 4.24 & 4.14 \\
\hline \multicolumn{4}{|l|}{ Eating disorders } \\
\hline Anorexia nervosa & 4.40 & 4.38 & 4.36 \\
\hline Bulimia nervosa & 4.42 & 4.47 & 4.55 \\
\hline \multicolumn{4}{|l|}{ Suicidality } \\
\hline Suicidal ideation & 4.32 & 4.17 & 4.04 \\
\hline Suicide plan or attempt & 4.33 & 4.17 & 3.99 \\
\hline \multicolumn{4}{|l|}{ Maternal mental health } \\
\hline Mother sad/depressed & 4.49 & 4.64 & 4.75 \\
\hline Mother had drinking problem & 4.36 & 4.25 & 4.12 \\
\hline Mother attempted suicide & 4.37 & 4.27 & 4.13 \\
\hline Mother treated for depression & 4.39 & 4.37 & 4.35 \\
\hline Mother treated for substance use & 4.37 & 4.30 & 4.20 \\
\hline \multicolumn{4}{|l|}{ Joint confounding } \\
\hline $\begin{array}{l}\text { Assuming biases from above-listed } \\
\text { confounders were independent }\end{array}$ & 4.22 & 3.57 & 3.10 \\
\hline
\end{tabular}

Results across the fuller continuum of possible confounder-suicide associations are presented in the online supplementary figure

practices that we have taken towards the presence of firearms in the home.

While the current study adds to the scientific discussion of firearm access and suicide risk, it should be interpreted in light of its own limits. First, our measure of living in a home with versus without a firearm was self-reported, which implies that this measure is a composite of actually having, awareness of having and willingness to accurately report having a firearm in the home. We conjecture, for example, that the observed association between sex and our measurement may be an artefact of awareness (since sex is previously accounted for in the study by Brent and colleagues, this conjecture does not change our primary conclusions). Second, our approach does not take into account the correlations among the various demographic and mental health characteristics, including their correlations with previously adjusted measures. For example, Brent and colleagues explicitly adjusted for major depressive disorder, which is correlated with many of the mental health characteristics considered here. Because of this, effect size adjustments based on the observed imbalances in these mental health characteristics, and therefore treated as though they are all independent from one another and from previously adjusted measures like major depressive disorder, will likely overestimate the amount of possible bias and thus adjust the effect estimate downward to a greater extent than would be the case if we were to consider their contributions jointly. Third, we only address unmeasured confounding; future studies could use analogous methods to examine how selection or information biases may impact effect estimates if it were suspected that these sources of potential bias are present in the existing studies. Fourth, we do not directly take on imminent reverse causation (ie, the apparent association between firearm availability and suicide in the literature being explained away by asserting that persons who intend to die by suicide go out and purchase a firearm to that end). While such confounding by suicide intent might theoretically pertain to the gun owner himself, reverse causation must be minimal or non-existent in a study of adolescents, who are not by and large the purchasers of the firearms used in their suicides. ${ }^{35} 36$ Fifth, though our bias analyses are applied to the seminal study by Brent and colleagues, the original study is, of course, a single study, and based on a sample of adolescents in one region in the US (western Pennsylvania). We implicitly assume that the effect estimate from the original study applies to the entire US adolescent population. That said, the effect estimates in their study closely align with those found in meta-analyses of observational studies of firearm access among all ages across the $\mathrm{USA}^{2}{ }^{15}$ as well as what is implied by age-stratified results in prior case-control and ecologic studies. ${ }^{8}$ Sixth, residual unmeasured confounding, beyond the adjustments we have made using data from the NCSA is always a possibility. It is important to note, however, that our set of measures encompass the scope of established suicide risk factors that, a priori, could meaningfully influence the effect estimates in a study of adolescents. Lastly, the data underlying our study (ie, the Brent and colleagues casecontrol study and the NCSA) were collected over 15 years ago and thus any conclusions about how the effect size would translate to present day adolescents would need to carefully consider whether any generational changes are relevant. To our knowledge, there is no reason to believe the relative risk would be dramatically different.

The criticism that unmeasured confounding cannot be ruled out has, in legal proceedings, policy decisions, and the scientific literature been exploited to manufacture an exaggerated degree of uncertainty about - and curbed efforts to reduce-the risk of suicide imposed by access to firearms. ${ }^{163738}$ Manufactured uncertainty of this kind has historically been exploited to impede public health initiatives, most famously by delaying initiatives to curb smoking, at the cost of many lives. ${ }^{39}$ Indeed, the uncertainty of all scientific inquiry, where knowledge remains provisional, subject to new discovery and re-evaluation, does not mean that uncertainty is unbounded or that efforts to quantify it are unimportant. In that light, our results serve as a reminder that although observational studies may well be biased due to unmeasured confounding, this theoretical possibility should not be viewed as license to disregard observational data, ${ }^{40-42}$ or, more importantly and fundamentally, to curb efforts grounded in quantified bounds of likely effect size to save lives by reducing access to firearms. After all, we should not avoid and have not avoided empirically based decision-making just because observational studies and not randomised trials are the basis for our collective conclusions about the dangers of smoking ${ }^{43}$ or the identification of teratogens. ${ }^{44} 45$

Although means restriction has been credited with saving more lives than any other suicide prevention strategy, ${ }^{46}$ and counselling parents to reduce access to household firearms has been endorsed by the American Academy of Pediatrics for over two decades, ${ }^{47}$ most clinicians do not routinely counsel parents to 
remove firearms from their homes or otherwise make firearms inaccessible to their children, even when their child presents to an emergency department in an acute crisis. ${ }^{48}$ One reason clinicians infrequently offer counselling may be that they do not believe that removing the guns really reduces the risk of suicide. By providing empirical context for interpreting the prior work by Brent and colleagues, in particular that study's relative resilience to residual confounding, the current paper strengthens the evidentiary base that can be used to inform clinician beliefs about the magnitude of the suicide risk conferred on youth by household firearms.

\section{CONCLUSION}

Our study contributes to the ongoing discussion of how firearm access affects suicide risk by adding empirical support in the form of a bias analysis that strongly suggests an adolescent's suicide risk is greatly increased if he or she lives in a home with versus without firearms, with a best estimate that the risk of dying by suicide is at least three times greater.

\section{What is already known on the subject}

- Strong and consistent associations between access to firearms and suicide have been found in prior studies. For adolescents, a seminal case-control study estimated that living in a home with a firearm was associated with a fourfold increase in suicide risk.

\section{What this study adds}

- Although unmeasured confounding and other biases may nonetheless remain, our updated estimates reinforce the suggestion that adolescents' risk of suicide is increased threefold to fourfold if they live in homes with a firearm compared to if they do not.

Contributors SS conceptualised and designed the study, contributed to the analyses, drafted the initial manuscript and reviewed and revised the manuscript. $M E, Y H S$ and MM contributed to the study design, performed analyses and critically reviewed and revised the manuscript. All authors approved the final manuscript as submitted and agree to be accountable for all aspects of the work.

Funding MM's time was supported, in part, by funding from the Joyce Foundation. SS is supported by a NWO/ZonMW Veni grant (91617066).

\section{Competing interests None declared.}

Patient and public involvement Patients and/or the public were not involved in the design, or conduct, or reporting or dissemination plans of this research.

Patient consent for publication Not required.

Provenance and peer review Not commissioned; externally peer reviewed.

Data availability statement Data are available in a public, open access repository. The NCSA is a restricted use, public access dataset for which the Interuniversity Consortium for Political and Social Research at the University of Michigan acts as a custodian (https://www.icpsr.umich.edu/web/HMCA/studies/28581https:// www.icpsr.umich.edu/web/HMCA/studies/28581).

Open access This is an open access article distributed in accordance with the Creative Commons Attribution Non Commercial (CC BY-NC 4.0) license, which permits others to distribute, remix, adapt, build upon this work non-commercially, and license their derivative works on different terms, provided the original work is properly cited, appropriate credit is given, any changes made indicated, and the use is non-commercial. See: http://creativecommons.org/licenses/by-nc/4.0/.

ORCID iD

Sonja A Swanson http://orcid.org/0000-0002-2535-9605

\section{REFERENCES}

1 Centers for Disease Control and Prevention NCfIPaC. Web-Based injury statistics query and reporting system (WISQARS), 2005. Available: www.cdc.gov/injury/wisqars [Accessed 17 Apr 2018].

2 Anglemyer A, Horvath T, Rutherford G. The accessibility of firearms and risk for suicide and homicide victimization among household members: a systematic review and meta-analysis. Ann Intern Med 2014;160:101-10.

3 Brent DA. Firearms and suicide. Ann N Y Acad Sci 2001;932:225-40.

4 Brent DA, Perper JA, Moritz G, et al. Firearms and adolescent suicide. A community case-control study. Am J Dis Child 1993;147:1066-71.

5 Cummings P, Koepsell TD, Grossman DC, et al. The association between the purchase of a handgun and homicide or suicide. Am J Public Health 1997:87:974-8.

6 Grassel KM, Wintemute GJ, Wright MA, et al. Association between handgun purchase and mortality from firearm injury. Inj Prev 2003:9:48-52.

7 Miller M, Azrael D, Hemenway D. Household firearm ownership and suicide rates in the United States. Epidemiology 2002:13:517-24.

8 Miller M, Azrael D, Hemenway D. Firearm availability and suicide, homicide, and unintentional firearm deaths among women. J Urban Health 2002;79:26-38.

9 Miller M, Hemenway D. Guns and suicide in the United States. N Eng/ J Med 2008:359:989-91.

10 Miller M, Lippmann SJ, Azrael D, et al. Household firearm ownership and rates of suicide across the 50 United States. J Trauma 2007:62:1029-35.

11 Wintemute GJ, Parham CA, Beaumont JJ, et al. Mortality among recent purchasers of handguns. N Engl J Med 1999;341:1583-9.

12 Caron J, Julien M, Huang JH. Changes in suicide methods in Quebec between 1987 and 2000: the possible impact of bill C-17 requiring safe storage of firearms. Suicide Life Threat Behav 2008:38:195-208.

13 Shenassa ED, Rogers ML, Spalding KL, et al. Safer storage of firearms at home and risk of suicide: a study of protective factors in a nationally representative sample. J Epidemiol Community Health 2004;58:841-8.

14 Brent DA, Baugher M, Bridge J, et al. Age- and sex-related risk factors for adolescent suicide. J Am Acad Child Adolesc Psychiatry 1999;38:1497-505.

15 Miller M, Swanson SA, Azrael D. Are we missing something pertinent? A bias analysis of unmeasured confounding in the Firearm-Suicide literature. Epidemiol Rev 2016:38:mxv011-69.

16 Kellermann AL, Rivara FP, Somes G, Kleck G, et al. Suicide in the home in relation to gun ownership. N Engl J Med 1992;327:467-72.

17 Miller M, Swanson SA, Azrael D. Are we missing something pertinent? A bias analysis of unmeasured confounding in the Firearm-Suicide literature. Epidemiol Rev; 160:mxv011.

18 Miller M, Barber C, Azrael D, et al. Recent psychopathology, suicidal thoughts and suicide attempts in households with and without firearms: findings from the National comorbidity study replication. Inj Prev 2009;15:183-7.

19 Sorenson SB, Vittes KA. Mental health and firearms in community-based surveys: implications for suicide prevention. Eval Rev 2008;32:239-56.

20 Simonetti JA, Azrael D, Miller M. Firearm storage practices and risk perceptions among a nationally representative sample of U.S. veterans with and without self-harm risk factors. Suicide Life Threat Behav 2019:49:653-664.

21 Ilgen MA, Zivin K, McCammon RJ, et al. Mental illness, previous suicidality, and access to guns in the United States. Psychiatr Serv 2008:59:198-200.

22 Merikangas KR, Avenevoli S, Costello EJ, et al. National comorbidity survey replication adolescent supplement (NCS-A): I. background and measures. J Am Acad Child Adolesc Psychiatry 2009;48:367-79.

23 Merikangas KR, He J-P, Burstein M, et al. Lifetime prevalence of mental disorders in U.S. adolescents: results from the National Comorbidity Survey Replication-Adolescent Supplement (NCS-A). J Am Acad Child Adolesc Psychiatry 2010;49:980-9.

24 Kessler RC, Avenevoli S, Costello EJ, et al. Design and field procedures in the US national comorbidity survey replication adolescent supplement (NCS-A). Int J Methods Psychiatr Res 2009;18:69-83.

25 Kessler RC, Avenevoli S, Costello EJ, et al. National comorbidity survey replication adolescent supplement (NCS-A): Il. overview and design. J Am Acad Child AdolesC Psychiatry 2009;48:380-5

26 Kessler RC, Avenevoli S, Green J, et al. National comorbidity survey replication adolescent supplement (NCS-A): III. concordance of DSM-IV/CIDI diagnoses with clinical reassessments. J Am Acad Child Adolesc Psychiatry 2009:48:386-99.

27 Green JG, Avenevoli S, Finkelman M, et al. Validation of the diagnoses of panic disorder and phobic disorders in the US national comorbidity survey replication adolescent (NCS-A) supplement. Int J Methods Psychiatr Res 2011;20:105-15.

28 Green JG, Avenevoli S, Gruber MJ, et al. Validation of diagnoses of distress disorders in the US national comorbidity survey replication adolescent supplement (NCS-A). Int J Methods Psychiatr Res 2012;21:41-51.

29 Husky MM, Olfson M, He J-ping, et al. Twelve-month suicidal symptoms and use of services among adolescents: results from the National comorbidity survey. Psychiatr Serv 2012;63:989-96.

30 Nock MK, Green JG, Hwang I, et al. Prevalence, correlates, and treatment of lifetime suicidal behavior among adolescents: results from the National comorbidity survey replication adolescent supplement. JAMA Psychiatry 2013;70:300-10. 
31 Vanderweele TJ, Arah OA. Bias formulas for sensitivity analysis of unmeasured confounding for general outcomes, treatments, and confounders. Epidemiology 2011;22:42-52.

32 Rothman KJ, Greenland S, Lash TL. Modern epidemiology. Lippincott Williams \& Wilkins, 2008.

33 Grossman DC, Mueller BA, Riedy C, et al. Gun storage practices and risk of youth suicide and unintentional firearm injuries. JAMA 2005;293:707-14.

34 Simonetti JA, Mackelprang JL, Rowhani-Rahbar A, et al. Psychiatric comorbidity, suicidality, and in-home firearm access among a nationally representative sample of adolescents. JAMA Psychiatry 2015;72:152-9.

35 Grossman DC, Reay DT, Baker SA. Self-Inflicted and unintentional firearm injuries among children and adolescents: the source of the firearm. Arch Pediatr Adolesc Med 1999;153:875-8.

36 Wright MA, Wintemute GJ, Claire BE. Gun suicide by young people in California: descriptive epidemiology and gun ownership. J Adolesc Health 2008;43:619-22.

37 Kleck G. Targeting guns: firearms and their control. Transaction Publishers, 1997.

38 Leshner Al, Altevogt BM, Lee AF, et al. Priorities for research to reduce the threat of firearm-related violence. National Academies Press, 2013.

39 Brandt AM. Cigarette century: The rise, fall, and deadly persistence of the product that defined America. New York: Basic Books, 2007.
40 Smith GCS, Pell JP. Parachute use to prevent death and major trauma related to gravitational challenge: systematic review of [randomized] controlled trials. J Int Assoc Physicians AIDS Care 2004;3:108-9.

41 Hernán MA. Invited commentary: hypothetical interventions to define causal effects-afterthought or prerequisite? Am J Epidemiol 2005;162:618-20.

42 Hernán MA. With great data comes great responsibility: publishing comparative effectiveness research in epidemiology. Epidemiology 2011;22:290-1.

43 Cornfield J, Haenszel W, Hammond EC, et al. Smoking and lung cancer: recent evidence and a discussion of some questions. J Nat/ Cancer Inst 1959;22:173-203.

44 Botting J. The history of thalidomide. Drug News Perspect 2002;15:604-11.

45 Palmsten K, Hernández-Díaz S. Can nonrandomized studies on the safety of antidepressants during pregnancy convincingly beat confounding, chance, and prior beliefs? Epidemiology 2012;23:686-8.

46 Azrael D, Miller M. Access to Lethal Means. A Review of the Evidence Base. In: O'Connor RC, Pirkis J, eds. The International Handbook of suicide prevention. 2 edn. West Sussex: John Wiley \& Sons, Ltd., 2016.

47 Council on Injury, Violence, and Poison Prevention Executive Committee. FirearmRelated injuries affecting the pediatric population. Pediatrics 2012;130:788-90.

48 Naureckas Li C, Sacks CA, McGregor KA, et al. Screening for access to firearms by pediatric trainees in high-risk patients. Acad Pediatr 2019;19:659-64. 